\title{
PENGARUH LATIHAN PLYOMETRICS OTOT TUNGKAI TERHADAP HASIL TENDANGAN PENALTI PADA CABANG OLAHRAGA FUTSAL
}

\author{
Aris Munandar ${ }^{1}$, Muhamad Syamsul Taufik ${ }^{2}$, Ravizah Eka Putri \\ Pendidikan Jasmani Kesehatan dan Rekreasi, Fakultas Keguruan dan Ilmu Pendidikan \\ Universitas Suryakancana,Indonesia \\ Am6289940@gmail.com ${ }^{1}$, syamsul @unsur.ac.id ${ }^{2}$,vizzahazz@gmail.com ${ }^{3}$
}

\begin{tabular}{l}
\hline \multicolumn{1}{c}{ Info Artikel } \\
\hline Sejarah Artikel: \\
Diterima Maret 2020 \\
Disetujui April 2020 \\
Dipublikasikan Juni 2020
\end{tabular}

Kata Kunci

Pengaruh, Latihan Plyometrics

Otot Tungaki, Hasil Tendangan

Keyword:

Influence, Tungaki Muscle

Plyometrics Exercise, Kick

Results

\begin{abstract}
Abstrak
Penelitian ini di latar belakangi oleh permasalahan dari hasil tendangan penalti dalam permainan futsal, tendangan penalti maupun tendangan adu penalti yang tidak masuk ke gawang, adapun faktor yang menentukan tendangan penalti fisik, teknik, taktik dan mental. Dalam penelitian ini yang di teliti yaitu teknik tendangan penalti. Tujuan dari penelitian ini adalah untuk mengetahui apakah terdapat pengaruh yang signfikan dari latihan plyometrics otot tungkai terhadap hasil tendangan penalti pada cabang olahraga futsal. Populasi dalam penelitian ini adalah 25 orang. Pengambilan sampel pada penelitian ini menggunakan teknik Purposive Sampling Atlet UKM Futsal Universitas Suryakancana Cianjur pada penelitian ini berjumlah 15 orang. Teknik pengambilan data yakni menggunakan teknik pretest dan posttest, sedangkan untuk analisis data menggunakan uji t. Berdasarkan hasil output dengan menggunakan SPSS 20 bahwa nilai rata-rata sebelum diberikan latihan plyometrics sebesar 10.40 , setelah diberikan perlakuan dengan latihan Plyometrics sebesar 17.67. Berdasarkan keterangan tersebut dapat dikatakan bahwa latihan plyometrics otot tungkai, dapat meningkatkan kemampuan tendangan penalti dalam permainan futsal.
\end{abstract}

\section{Abstrack}

This research is in the background of the problems of the results of penalty kicks in futsal games, penalty kicks and penalty shoot-outs that do not enter the goal, as for the factors that determine physical, technical, tactical and mental penalty kicks. In this study, it was examined the penalty kick technique. The purpose of this study was to find out whether there was a significant effect of leg muscle plyometrics training on the results of penalty kicks in futsal sports. The population in this study were 25 people. Sampling in this study used the Purposive Sampling technique of Futsal UKM Athletes in Suryakancana University Cianjur in this study amounted to 15 people. Data collection techniques were using the pretest and posttest techniques, while for data analysis using the t test. Based on the results of the output using SPSS 20 that the average value before being given plyometrics training was 10.40, after being given treatment with Plyometrics exercise of 17.67. Based on this information it can be said that leg muscle plyometrics exercises can increase the ability of penalty kicks in futsal games. 


\section{PENDAHULUAN}

Futsal masuk ke Indonesia berkisaran antara tahun 1998-1999 dan masyarakat mulai mengenal dengan baik pada tahun 2000-an. Pada saat itulah futsal mulai berkembang dengan pesat diikuti lahirnya banyak sekolah-sekolah futsal di Indonesia.(Yuniarto, Supriyadi, \& Sudjana, 2018). Dalam permainan futsal teknik dasar adalah hal yang sangat penting merupakan modal utama pemain menguasai teknik-teknik dasar termasuk tendangan pinalti. Teknik dasar menendang bola juga sering digunakan sebagai senjata yang paling ampuh untuk mencetak gol melalui titik penalti, bahkan pertandingan futsal yang dilaksanakan dengan waktu yang singkat sering membuat pertunjukan yang menarik dalam laga adu penalti, maka dari itu dibutuhkan power tendangan dan akurasi yang baik agar bola masuk ke gawang tidak terblok oleh penjaga gawang.

Dalam pendidikan menjamin agar pembelajaran pada program studi, penelitian, dan pengabdian kepada masyarakat yang diselenggarakan oleh perguruan tinggi di seluruh wilayah hukum Negara Kesatuan Republik Indonesia mencapai mutu sesuai dengan kriteria yang ditetapkan dalam Standar Nasional Pendidikan Tinggi.(Switri \& Yusfi, 2019).
Pendidikan dasar merupakan pondasi untuk pendidikan selanjutnya dan pembangunan nasional, untuk itu mutu pendidikan dasar perlu ditingkatkan dan peningkatan itu hendaknya ber- laku menyeluruh, termasuk didalamnya adalah Pendidikan Jasmani Olahraga dan Kesehatan (Penjasorkes)(Febrianti, 2013). Berdasarkan hasil observasi perkembangan Futsal di Universitas Surayakancana Cianjur, perkembangan futsal di Universitas Suryakancana Cianjur sedang mengalami perkembangan yang cukup signifikan, baik dari segi infrastruktur dengan tersedianya lapangan Futsal, pembinaan, dan sumber daya manusia atau kualitas altet. Di Universitas Suryakancana sudah terbentuknya UKM Futsal yang menjadi wadah pembinaan bagi Mahasiswa yang ingin mengembangkan bakatnya dalam cabang permainan futsal, UKM Futsal Universitas Suryakancana Cianjur sudah banyak mengikuti kejuaraan baik di daerah kab Cianjur, di tingkat Jawa Barat, dan kompetisi antar Mahasiswa se Jawa barat. Prestasi UKM Futsal Universitas Suryakancana memang belum di tingakat puncaknya karena terhenti di babak selanjutnya baik itu di 16 besar atau 8 besar dari Universitas yang sudah maju baik dari segi pembinaan atau sumber daya manusia nya, namun dalam permainan setidaknya sudah bisa mengimbangi Universitas 
3 | Aris Munandar ${ }^{1}$, Muhamad Syamsul Taufik ${ }^{2}$

Pengaruh Latihan Plyometrics Otot Tungkai Terhadap Hasil Tendangan Penalti

Pada Cabang Olahraga Futsal

lainnya dari data yang di lihat dari

Turnamen di Universitas Pakuan Bogor

Rektor Cup 2018, Unsur terhenti di per delapan besar lewat adu Penalti.

Sehingga melihat fenomena yang nyata dilapangan pada tim UKM Futsal Universitas Suryakancana perlunya peningkatan kondisi fisik dan teknik khususnya kemampuan daya ledak otot tungkai untuk menunjang akurasi dan kekuatan kemampuan menendang ke arah gawang, karena dilihat dari hasil diatas membuat peneliti tertarik membahas penelitian tersebut. Melihat dari permasalahn tersebut, maka peneliti ingin melakukan penelitian untuk mengetahui "Pengaruh Latihan Plyometrics Otot Tungkai Terhadap Hasil Tendangan Penalti Pada Cabang Olahraga Futsal”.

Adapun tujuan penelitian ini tidak lain adalah bertitik tolak dengan rumusan masalah yang ada yakni adalah Apakah terdapat Pengaruh yang Signifikan Latihan Plyometrics Otot Tungkai Terhadap Hasil Tendangan Penalti Pada Cabang Olahraga Futsal Di UKM Futsal Universitas Suryakancana Cianjur.

\section{METODE}

Dalam penelitian ini adalah metode eksperimen. Desain yang digunakan dalam penelitian ini adalah "One Group Pre test-

Post test Design"

\section{$\mathrm{O}_{1} \mathrm{X} \mathrm{O}_{2}$}

(Sugiono, 2013)

Keterangan :
O1 (pre-test): dilakukan test awal menendang bola sebelum diberikan treatment

$\mathrm{X}$ : perakuan atau latihan plyometrics

$\mathrm{O} 2$ (post-test) : dilakukan test akhir menendang bola sesudah diberikan treatment

Penelitian ini termasuk penelitian eksperimen, menurut Sugiyono (2015) bahwa metode penelitian eksperimen merupakan metode penelitin yang digunakan untuk mencari pengaruh treatment (perlakuan tertentu). (hlm. 6). penelitian ini adalah eksperimen.

\section{HASIL DAN PEMBAHASAN}

Latihan yang terprogram adalah latihan yang memiliki tujuan yang jelas, materinya sesuai dengan nomor olahraga yang dilatih, waktunya juga jelas.(Negeri \& Trenggalek, 2018). Latihan adalah proses sistematis untuk menyempurnakan kualitas kinerja atlet berupa : kebugaran, dan kapasitas energy. Materi latihan dirancang dan disusun oleh pelatih satu sesi latihan atau satu kali latihan tatap muka dalam latihan. Misalnya, susunan materi latihan dalam satu kali tatap muka pada umumnya berisikan materi yang antara lain : (1) Pembukaan/pengantar latihan, Pemanasa (warming up), (3) Latihan inti, (4) Latihan tambahan (suplemen, dan (5) (cooling down). (Harsono, 2017) Pada cabang olahraga futsal ada beberapa factor yang sangat mendukung terwujudnya kemampuan bermain futsal yang baik, baik 
4 | Aris Munandar ${ }^{1}$, Muhamad Syamsul Taufik ${ }^{2}$

Pengaruh Latihan Plyometrics Otot Tungkai Terhadap Hasil Tendangan Penalti

Pada Cabang Olahraga Futsal

itu factor fisik, teknik, taktik maupun mental (Badaru, B, 2017) Pada faktor teknik, salah satu terwujudnya bermain futsal yang baik ialah tendangan, khususnya tendangan pinalti. Tugas pelatih perlu mencari model latihan yang efektif yang dapat meningkatkan kemampuan atlet(Teguh Dwi P, Sudrajat W, Bambang KS, 2018).

Sedangkan mekanika adalah salah satu cabang ilmu dari bidang ilmu fisika yang mempelajari gerakan dan perubahan bentuk suatu materi yang diakibatkan oleh gangguan mekanik yang disebut gaya.(Rusdiana, Sartono, Nurjaya, \& Angga, 2019). Dalam permainan futsal teknik dasar adalah hal yang sangat penting merupakan modal utama pemain menguasai teknik-teknik dasar termasuk tendangan pinalti. Futsal menuntut kondisi fisik yang baik agar dapat menunjang penampilan.(Furqoni \& Sudijandoko, 2019) Penampilan fisik yang buruk akan berdampak pada buruknya penampilan teknik dan taktik. Teknik dasar menendang bola juga sering digunakan sebagai senjata yang paling ampuh untuk mencetak gol melalui titik penalti, bahkan pertandingan futsal yang dilaksanakan dengan waktu yang singkat sering membuat pertunjukan yang menarik dalam laga adu penalti, maka dari itu dibutuhkan power tendangan dan akurasi yang baik agar bola masuk ke gawang tidak terblok oleh penjaga gawang.
Dalam penelitian ini desain yang digunkan ialah One-Group Pretest-Posttest Design yang dimaksudkan untuk mengetahui ada tidaknya akibat dari treatment yang dikenakan pada sampel penelitian. Kemudian pada pretest dan posttest di lakukan tes tendangan ke gawang yang tujuannya untuk mengetahui hasil ketepatan, setiap penendang diberi 3 kali kesempatan dan di hitung waktu pada saat penendang perkenaan dengan bola dan bola mengenai nomor digawang yang sudah diberi angka. Penelitian ini mengkaji tentang pengaruh latihan plyometrics terhadap hasil tendangan penalty pada cabang olahraga futsal di UKM Universitas Suryakancana Cianjur. Yang terdiri dari 15 atlet, kemudian dilakukan pre test atau tes awal dimaksudkan untuk megetahui hasil tendangan atlet sebelum diberikan treatmen atau tindakan, kemudian diberikan treatmen yaitu delapan (8) bentuk latihan plyometrics dengan tambahan delapan menggunakan bola dengan total latihan enam belas (16) pertemuan. Kemudian dilakukan post test atau tes akhir untuk mengetahui hasil tendangan sesudah diberikan treatmen atau tindakan.

Dalam uji normalitas data yang dihasilkan diketahui bahwa nilai signifikan Asiymp.sig (2-talled) sebesar 0,766 lebih besar dari 0,05 maka sesuai dengan pengambilan keputusan dalam uji nirmalitas kolmogorov smirnov, dapat dinyatakan bahwa data berdistribusi 
5 | Aris Munandar ${ }^{1}$, Muhamad Syamsul Taufik ${ }^{2}$

Pengaruh Latihan Plyometrics Otot Tungkai Terhadap Hasil Tendangan Penalti

Pada Cabang Olahraga Futsal

normal. Berdasarkan data dari uji homogenitas "Test Of Homogenity of Varuances" diketahui nilai signifikan (sig.) variabel hasil tendangan penalti adalah sebesar 0,085. Karena nilai Sig.0,085 $>0,05$ maka sebagaimana dasar pengambilan keputusan dalam uji homogenitas di atas, dapat disimpulkan bahwa varian data hasil tendangan penalti adalah sama atau homogen.

Berdasarkan hasil penelitian diketahui bahwa diperoleh hasil rata-rata tes hasil tendangan penalti pada atlet UKM futsal Universitas Suryakancana Cianjur pre test sebesar 10.40 dan nilai rata-rata post test sebesar 17.67 artinya bahwa rata-rata pada terdapat peningkatan.Berdasarkan hasil penelitian, maka dibawah dijabarkan grafik hasil pretest dan posttest hasil tendangan penalti.

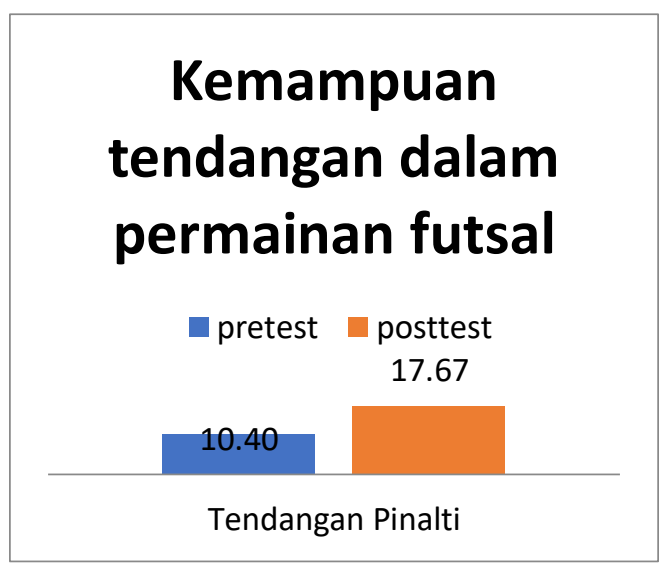

\section{SIMPULAN}

Berdasarkan pemaparan data hasil penelitian dan pembahasan di atas, maka hasil penelitian ini dapat ditarik kesimpulan sebagai berikut: Ada Pengaruh
Latihan Plyometrics Otot Tungkai Terhadap Hasil Tendangan Penalti Pada Cabang Olahraga Futsal Di UKM Futsal Universitas Suryakancana Cianjur.

\section{DAFTAR PUSTAKA}

Badaru, B. (2017). Latihan Taktik BEYB Bermain Futsal. Cakrawala Cendekia, Bekasi

Daya, K., Otot, L., Terhadap, T., Fakultas, O., Keolahragaan, I., Padang, N., ... Padang, U. N. (2015). Kontribusi daya ledak otot tungkai terhadap kemampuan lari 100 meter mahasiswa pendidikan olahraga fakultas ilmu keolahragaan universitas negeri padang.

Febrianti, R. (2013). Pengembangan materi atletik melalui permainan atletik. Semarang, Universitas Negeri Semarang, 2(1).

Furqoni, R. S., \& Sudijandoko, A. (2019). R.futqoni, A Sudijandoko. 5.

Harsono, (2017). Kepelatihan Olahrag. PT Remaja Rosdarkarya. Bandung Muhamad Syamsul Taufik, Muhamad Guntur Gaos, 2019/11/1 Peningkatan Hasil Belajar Dribbling Sepakbola Dengan Penggunaan Media Audio Visual Jurnal, Jp. jok (Jurnal Pendidikan Jasmani, Olahraga dan Kesehatan) Jilid 3, 1 hlm. $43-54$ 
6 | Aris Munandar ${ }^{1}$, Muhamad Syamsul Taufik ${ }^{2}$

Pengaruh Latihan Plyometrics Otot Tungkai Terhadap Hasil Tendangan Penalti

Pada Cabang Olahraga Futsal

Negeri, S. D., \& Trenggalek, T. (2018).

permainan bola voli pada

Peningkatan Hasil Belajar Lari

mahasiswa

Cepat 100M melalui Metode Latihan

Akselerasi. 2(1), 24-29.

Teguh Dwi P, Sudrajat W, Bambang KS, W. (2018). JUARA : Jurnal

Olahraga. JUARA : Jurnal Olahraga, 3(2). Retrieved from \& Angga, M. (2019). Analisis perbedaan long drive swing mechanical movement terhadap ball velocity berbasis pendekatan kinematics analysis antara skill dan unskill golf player Difference analysis of long drive swing mechanical movement towards ball velocity based on analysis kinematics approach between skill and unskill golf player.

Sugiyono, (2013). Metode Penelitian Pendidikan. Afabeta. Bandung

Switri, E., \& Yusfi, H. (2019). q2AszA

Widiastuti, (2015). Tes Dan Pengukuran olahraga. PT Rajagrafindo. Jakarta

Yuniarto, A., Supriyadi, S., \& Sudjana, I. N. (2018). Pengembangan Media Pembelajaran Berbasis Mobile Learning Teknik Dasar Dan Peraturan Permainan Futsal. JP.JOK (Jurnal Pendidikan Jasmani, Olahraga Dan Kesehatan), 2(1), 51-62. https://doi.org/10.33503/jpjok.v2i Pengembangan pembelajaran 